\title{
A prática da psicoterapia infantil na visão de terapeutas nas seguintes abordagens: psicodrama, Gestalt terapia e centrada na pessoa
}

\author{
The child psychotherapy practice according \\ to the following approaches: psychodrama, Gestalt \\ therapy and person-centered
}

\author{
Maria Ivone Marchi COSTA \\ Cristina Maria Souza Brito DIAS²
}

\begin{abstract}
Resumo
Este trabalho objetivou conhecer como psicoterapeutas - de psicodrama, Gestalt terapia e abordagem centrada na pessoa (dois de cada abordagem) - que trabalham com crianças experienciam sua prática cotidiana. A pesquisa qualitativa utilizou entrevistas semidirigidas para o levantamento dos dados. A análise e a discussão dos resultados basearam-se na literatura consultada e permitiram concluir que os sentimentos experimentados são a valorização do caráter preventivo do trabalho com a criança, a frustração, a solidão e a impotência quando não contam com a colaboração dos pais. Em relação aos obstáculos enfrentados, têm-se a dificuldade em obter aliança com os pais, o pequeno número de profissionais atuantes na especialidade e a escassez de pesquisas e literatura. Os recursos utilizados são a rede social da criança, brinquedos (estruturados ou não), testes e técnicas; as necessidades sentidas são a atualização constante e a troca de experiência com outros profissionais. Em relação à avaliação da especialidade, conclui-se que a atuação na área requer esforço físico, compreensão da linguagem infantil e superação das limitações da própria formação.
\end{abstract}

Palavras-chave: Gestalt terapia; psicodrama; psicoterapeutas; psicoterapia da criança.

\begin{abstract}
The present study has investigated how is the daily practice of children's therapists from Psychodrama, Gestalt Therapy and Person-Centered (two of each approach). Semi guided interviews had been used to the qualitative data research, and the analysis of the results were based on the adequate literature. This study has appraised consequent feelings as the children's treatment preventive issue, and the frustration, loneliness and impotence as feelings related to those cases when parents don't want to be part of the process. Also, the difficulties in establishing parents'link or cooperation, and lack of specialized professionals, literature and researches was considered the obstacles of these therapy approaches practices. Children's therapy practice uses resources such as toys, children's social net, tests, techniques; and requires the professionals' good health condition, children's language comprehension ability, and the to overcome the graduation limitations.
\end{abstract}

Key words: Gestalt therapy; psychodrama; psychotherapists; child psychotherapy.

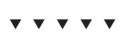

- Departamento de Psicologia, Universidade do Sagrado Coração de Bauru. Rua Irmã Arminda, 10-50, 17044-160, Bauru, SP, Brasil. Correspondência para/Correspondence to: M.I. M. COSTA. E-mail: <marchicosta@travelnet.com.br>.

2 Pós-Graduação em Psicologia Clínica, Universidade Católica de Pernambuco. Recife, PE, Brasil. 
O psicoterapeuta infantil com orientação de base humanista-existencial tem como meta realizar um trabalho clínico no qual exercer o papel de facilitador do autoconhecimento, possibilitando à criança vivenciar e experienciar a liberdade e o poder de escolha por meio de espaço, escuta, nominação de seus desejos e respeito pela sua singularidade. Deve propiciar, ainda, o reencontro consigo mesmo e a emergência de outras possibilidades por intermédio das quais possa encontrar recursos para ressignificar o sofrimento psíquico, denunciado ou não em forma de sintomas. Essas, possivelmente, tenham sido as manifestações que motivaram a busca, geralmente dos pais ou responsáveis, pelos serviços profissionais de um psicoterapeuta.

Para o psicoterapeuta clínico infantil, de orientação de base humanista-existencial, quase sempre são inquietantes a solidão de se atuar nessa especialidade e as abordagens quando o assunto é troca de experiência com outros profissionais da mesma área. A escassez de congressos e cursos voltados para essa prática é também outra dificuldade constante a ser enfrentada. É possível encontrar um certo número de referências bibliográficas sobre o desenvolvimento infantil ou teorias de personalidade, psicopatologia, psicomotricidade. No entanto, quanto a teorias da prática, são poucas as opções na literatura. Essa carência é sentida especialmente nas abordagens terapêuticas psicodrama, Gestalt terapia e centrada na pessoa, direcionadas à prática infantil - que necessitam de atualizações e/ou complementações por meio de parceria com outros autores e/ou busca e traduções de textos vindos do exterior.

A dificuldade de conseguir estabelecer uma aliança com os pais ou responsáveis e, por conseguinte, a sua colaboração no processo terapêutico da criança, também produz no terapeuta um sentimento de impotência e solidão. Não que o processo somente com a criança não possa avançar, mas, sem dúvida, a colaboração dos pais ou responsáveis aumenta as chances de aproveitamento.

Diante dessas questões, este trabalho buscou investigar junto a psicoterapeutas que trabalham com crianças com diferentes abordagens teóricas (psicodrama, Gestalt terapia e centrada na pessoa) como está 44 sendo experienciada a sua prática cotidiana, sinteti- zando-a nas seguintes dimensões: sentimentos experimentados; obstáculos vivenciados; recursos utilizados; necessidades sentidas e avaliação da especialidade, categorias que emergiram como as mais relevantes por ocasião da análise das entrevistas.

\section{Método}

Esta pesquisa, de caráter qualitativo, foi realizada com seis psicoterapeutas humanistas-existenciais (psicodrama, Gestalt terapia e centrada na pessoa), do sexo feminino, que trabalham com crianças, sendo duas de cada abordagem. Com exceção de uma psicoterapeuta (centrada na pessoa) que tinha 30 anos de experiência como psicóloga clínica infantil, as demais tinham entre 10 e 18 anos de experiência. Três das psicoterapeutas - uma de cada abordagem - eram também professoras do curso de graduação de psicologia e supervisoras em clínica-escola em universidades particulares. Todas as terapeutas entrevistadas eram da cidade de Recife, Estado de Pernambuco. A dificuldade em encontrar psicoterapeutas do sexo masculino que atuassem na prática infantil determinou que as entrevistas se realizassem apenas com terapeutas do sexo feminino.

Utilizaram-se entrevistas semidirigidas como instrumento de pesquisa por propiciarem a emergência dos conteúdos de forma espontânea, singular e livre. O início da entrevista com cada colaboradora se deu mediante a seguinte questão estimuladora: "Me conte sobre a sua experiência de ser uma psicóloga clínica infantil". A pesquisadora fez, ainda, algumas perguntas visando à ampliação e/ou à compreensão das respostas. As entrevistas foram realizadas individual e pessoalmente com as colaboradoras, sendo gravadas em fita cassete, transcritas na íntegra e analisadas qualitativamente. A análise e a discussão dos resultados tiveram por base a literatura consultada.

\section{Resultados e Discussão}

Como já referido, após a transcrição das entrevistas, observou-se que as respostas poderiam ser agrupadas em cinco temas comuns: sentimentos experimentados, obstáculos ou dificuldades sentidas no exercício profissional, recursos utilizados, 
necessidades sentidas e avaliação da especialidade. As psicoterapeutas também fizeram outras observações que foram relacionadas.

\section{Sentimentos experimentados}

As psicoterapeutas relataram que trabalhar com crianças é algo muito valioso pela possibilidade de uma ação precoce e/ou preventiva, tornando-se gratificante pela contribuição que representa junto à criança, família e sociedade. A espontaneidade da criança na sua comunicação verbal e não-verbal normalmente favorece o vínculo entre profissional e cliente e, conseqüentemente, a evolução da criança no processo terapêutico tende a ser naturalmente mais rápida, salvo quando a colaboração da sua rede social é imprescindível, mas inexistente.

Tais resultados evidenciaram a necessidade de estabelecer uma comunicação efetiva entre terapeuta e criança, sendo importante a atenção que o profissional deve dar à sua própria linguagem, disponibilizando-se a sair do mundo adulto e intelectualizado para alcançar o mundo lúdico da criança, com todo o seu simbolismo. Conectar-se com a capacidade cognitiva da criança no seu momento evolutivo, colocando-se aberto à gama de conteúdos nem sempre verbais que a criança desenvolve é imprescindível ao terapeuta, que apenas dessa forma poderá eliminar o abismo existente entre ambos, muitas vezes reforçado até pela própria diferença da estrutura física do adulto. Assim sendo, é bem possível que a criança o compreenda e se sinta compreendida.

Para Axline (1980b), o terapeuta deve se apresentar amigavelmente adulto e digno, trazendo à sala de terapia algo mais que sua presença, lápis e papel: é necessário que a criança confie no terapeuta. Segundo Oaklander (1980), o terapeuta deve se mover junto com a criança no sentido de saber quando falar e quando permanecer em silêncio. Para Bermúdez (1997), a tarefa do diretor (terapeuta) é a de acompanhar e seguir o protagonista (cliente) na busca de sua verdade, oferecendo-lhe, para que possa encontrá-la, todos os recursos pessoais, técnicos e metodológicos de que dispõe.

De acordo com Grandesso (2000b), trabalhar com crianças exige do terapeuta a habilidade de aproveitar ou criar oportunidades desde o momento em que se vê frente a frente com a criança: desenvolver uma conversação em torno de seus interesses, habilidades, conhecimentos e particularidades, de modo que ela possa emergir como sujeito e possa ser levada a sério, mesmo durante a brincadeira. Mais do que isso, na visão dessa autora, trabalhar com a criança envolve poder falar, de modo lúdico, das dificuldades, mas de modo suficientemente sério para gerar alternativas de mudança. A autora complementa que o grande desafio para o psicoterapeuta assim orientado está em inserir-se no mundo da criança, deixar-se conduzir pela curiosidade genuína, permitir-se admirar o material trazido por ela, usando a riqueza da imaginação infantil. Enfatiza, também, que embora o psicoterapeuta tenha muitos planos e objetivos, não deve haver expectativas: cada sessão é uma experiência existencial; o que tiver que acontecer acontecerá. É importante manter uma atitude que sustente o potencial pleno e saudável da criança, num ambiente de segurança e de respeito às suas capacidades e sentimentos.

Nesse sentido, Epston (1997) considera como tarefa do psicoterapeuta assistir a criança na produção de conhecimento, gerando suas próprias soluções. Para o autor, a estranheza que tal afirmação pode causar decorre do fato de, habitualmente, o adulto esperar que a criança o leve a sério tentando trazê-la para o mundo adulto em vez de considerá-la seriamente, procurando compreender o seu mundo.

Axline (1980), em seu sexto princípio psicoterápico, alerta sobre a responsabilidade do psicoterapeuta quando entra no mundo da criança para que tenha o cuidado de não ser invasivo, de maneira que a criança não seja bloqueada pela intromissão de sua personalidade no momento de brincar. É importante estar atento às suas sinalizações e indicações de caminhos, ficando o terapeuta na condição de acompanhá-la.

Oaklander (1980) ratifica esse aspecto ao salientar que o psicoterapeuta tem que ter a habilidade de não ser invasor, de ser leve e delicado sem ser demasiadamente passivo.

Paradoxalmente a esses aspectos que tornam o trabalho valioso e gratificante, sentimentos como frustração, solidão e impotência também acompanham 
a prática dessa especialidade no que se refere à dependência que o processo psicoterápico da criança tem em relação aos pais ou à rede social. Embora se encontrem pais que cresçam muito com o processo e sejam exímios colaboradores, há outros que, por razões diversas, acabam por dificultar o processo de crescimento de seus filhos. Isso deixa o profissional solitário, impotente e frustrado, já que a criança tem pouca autonomia, ou seja, ela é dependente deles até mesmo para iniciar ou suspender o processo.

Acredita-se que muito da resistência, principalmente dos pais, é decorrente da crença de que serão apontados como culpados pelos problemas da criança e que o psicoterapeuta estará ali desempenhando o papel de denunciador dessa culpa, crucificando-os. Tais sentimentos que permeiam o imaginário dos pais, provavelmente, são decorrentes de práticas que ainda se apóiam numa visão que foca mais as deficiências do que as competências e que acabam por desqualificar o saber dos pais, salientando o saber do terapeuta, que é o especialista, já que estudou para isso. Concorda-se com Grandesso (2000a) quando afirma que posturas terapêuticas respaldadas num posicionamento em que o terapeuta é o expert do conhecimento contribuem para dificultar a parceria com a rede social da criança, minimizando o trabalho colaborativo, tornando vulnerável o processo, despertando sentimentos de solidão, impotência e frustração nos terapeutas.

Acredita-se que esse tipo de prática acentue a dificuldade de conseguir um trabalho colaborativo, isente a família como co-participante do processo da criança, possibilitando campo fértil em predispô-la a desenvolver resistências e, assim, dificultar o processo de parceria. Isso pode ter influência na motivação do profissional, inclusive desmotivando-o a continuar a se dedicar a essa especialidade. Entretanto, sugerem-se pesquisas futuras a esse respeito.

A maturidade emocional do psicoterapeuta e a experiência profissional na área são citadas - tanto pelas colaboradoras como pela literatura - como propulsora do desenvolvimento de uma habilidade maior na articulação entre teoria e prática, especialmente no que concerne ao âmbito familiar. Destaque-se que isso propicia ao profissional uma maior segurança, que será refletida numa ação mais efetiva na articulação e 46 viabilização da conquista da aliança terapêutica, atenuando as dificuldades quanto à cooperação da rede social da criança, favorecendo uma maior efetividade nos resultados do processo.

Nessa dimensão, ainda, os psicoterapeutas também relataram experienciar solidão profissional, visto que há poucos terapeutas atuando na área de psicoterapia infantil nas abordagens pesquisadas, o que inviabiliza trocas de experiência e encaminhamentos.

\section{Obstáculos ou dificuldades no exercício profissional}

Um dos maiores obstáculos apontados na prática da psicoterapia infantil diz respeito à dificuldade de se conseguir o apoio dos pais. Além disso, as participantes acrescentaram que há poucos profissionais trabalhando na área e que a literatura é escassa. A dificuldade de se conseguir aliança com os pais ou outros membros significativos da rede social da criança é algo que se destaca na prática clínica infantil. Muitas vezes o progresso terapêutico da criança fica estagnado por questões pessoais dos pais, especialmente quando não aceitam ajuda.

Mesmo diante desses limites, quatro das psicoterapeutas afirmaram que continuam investindo na criança, acreditando que, de alguma forma, ela será beneficiada pela terapia, pois é melhor uma ajuda limitada do que nenhuma. As demais preferem não atender a criança quando não têm o apoio dos pais, principalmente se perceberem que as dificuldades da criança têm relação direta com o contexto familiar. Acreditam que mesmo que a criança esteja em psicoterapia não conseguirá transferir o crescimento conseguido, já que as forças contrárias serão constantes e por parte de pessoas que Ihe são significativas. Esse posicionamento ratifica a posição de Dorfman (1974), que considera que é demais pedir a uma criança pequena que lide sozinha com as relações, muitas vezes inflexíveis e traumatizantes, com os pais.

Oaklander (1980), a esse respeito, relata que é importante ajudar a criança a fazer as escolhas que quiser e a compreender quando elas são impossíveis, destacando que é de grande importância auxiliá-la na compreensão de que não pode assumir responsabilidades por aquilo que não pode escolher. 
Outro obstáculo vivenciado pelas terapeutas refere-se ao pequeno número de profissionais que atuam nessa especialidade, dificultando assim uma troca mútua e os encaminhamentos. Logo, se existem poucas pessoas trabalhando na prática clínica e, considerando que a teoria é fruto dela, então são também escassas as pesquisas bem como a literatura a respeito da prática infantil nas abordagens estudadas. Esses obstáculos têm toda uma repercussão na motivação das pessoas para trabalhar com crianças.

\section{Recursos utilizados}

Através das falas, pôde-se distinguir dois tipos de recursos usados pelas terapeutas: a rede social da criança e os recursos técnicos. Quanto à rede social, as psicoterapeutas acreditam na importância da família como recurso fundamental para auxiliar o processo da criança. Entendem também que, muitas vezes, a criança é o paciente identificado, o denunciador de toda a disfuncionalidade familiar.

É consenso entre as terapeutas que a família pode atuar como colaboradora e mantenedora do sintoma da criança e, nesse caso, colocam em dúvida os resultados da psicoterapia infantil quando não se faz um trabalho conjunto com a família. Todas trabalham com a rede social da criança; no entanto, a forma de trabalhar é que varia de orientação. Para elas, a terapia deveria possibilitar aos familiares serem atores ativos de sua história e não apenas a platéia que assistirá e receberá todas as informações a respeito de como recuperar as circunstâncias que estão produzindo sofrimento. O fato de não se colocar como pessoas que participam como agentes transformadores de sua própria história os isenta de uma maior responsabilidade, tornando a relação com o psicoterapeuta e com o processo psicoterápico superficial e pouco comprometida, sendo, assim, mais difícil conquistar o crescimento.

Convém ressaltar que, assim como Grandesso (2000b), entende-se como imprescindível respeitar os conhecimentos dos pais da criança em relação ao problema que vivem. Como protagonistas da história vivida, seu conhecimento caracteriza-se como uma espécie de "conhecimento a partir de dentro". Os pais, por viverem com a criança, conhecem-na muito melhor que qualquer terapeuta, tomando como referência o seu lugar como pais. Comunga-se também com tais idéias, pois se entende que os pais têm recursos naturais, na prática de convivência com a criança, que podem ser mobilizados terapeuticamente.

Grandesso (2000b) considera importante que o terapeuta esteja atento quanto aos ganhos, perdas, apreensões, medos e aborrecimentos, ações, narrativas organizadoras dos problemas que os membros da família vivem, que podem favorecer ou dificultar a busca de alternativas de mudança.

Em relação aos recursos técnicos, de maneira geral, as psicoterapeutas utilizam brinquedos e outros recursos normais de uma sala de ludoterapia - previstos na abordagem que têm como diretriz -, que variam entre estruturados e não estruturados, sendo os últimos priorizados pelas psicoterapeutas psicodramatistas.

As terapeutas também consideram o valor de se utilizarem como recurso algumas técnicas de outras abordagens, desde que com conhecimento, responsabilidade e concordância do cliente. Molina-Loza (2002) partilha essa idéia, considerando que se servir de um tipo de abordagem não implica, necessariamente, abandonar todas as outras. Para o autor, uma forma de intervir que fosse igualmente válida para todo mundo representaria um empobrecimento, pois não se utilizaria essa ou aquela abordagem segundo os problemas apresentados pelos clientes, mas se adaptariam os clientes aos limites das teorias. Infelizmente, é isso que acaba acontecendo quando se"pertence" a um modelo.

Assim, quanto à utilização de técnicas, concorda-se com os psicodramatistas Bermúdez (1997), e Ferrari (1984), Oaklander (1980; 1994; 1999; 2000), da Gestalt terapia, e Axline (1980a, 1980b), da abordagem centrada na pessoa, de que a técnica para a prática infantil é necessária como instrumento mediador de comunicação, mas não deve ser tomada como um fim.

\section{Necessidades sentidas pelas psicoterapeutas}

As psicoterapeutas entendem que, além do aperfeiçoamento permanente, é igualmente importante estarem atualizados em relação ao universo infantil de maneira geral: suas brincadeiras, linguagem, jogos que estão no mercado, literatura, programas de TV, músicas, informática, vida escolar por meio de visitas à 
escola que a criança freqüenta, enfim, conhecer o cotidiano dessa criança no país, no estado, na cidade e na sua família.

É ainda sentido como necessidade estarem atentos ao trabalho pessoal do profissional por meio de psicoterapias, já que a sua criança está constantemente sendo acionada. Revisar a prática mediante supervisões e trocas entre profissionais é também uma necessidade. Infelizmente, em virtude de existirem poucos profissionais que atuem nessa especialidade, há dificuldade nesse sentido, assim como dificuldade em encaminhamentos e indicações.

Essa carência se estende, conseqüentemente, para a literatura da teoria e prática dessa especialidade, que é pouca e desatualizada. Os profissionais interessados têm de buscar apoio em outras abordagens e fazer um esforço grande de articulação para que não fique fragmentada. Nesse sentido, Osório e Valle (2002) fazem uma ressalva: trabalhar com distintos marcos referenciais teóricos requer um nível de habilitação ao qual só têm acesso profissionais mais experientes.

Também foi relatada uma carência muito grande em relação a congressos, palestras e cursos voltados para a prática clínica infantil.

\section{Avaliação da especialidade}

As psicoterapeutas acreditam que a prática clínica infantil está restrita por ser mais difícil trabalhar com a criança, e por exigir do profissional a compreensão da linguagem simbólica manifesta pela criança através da fantasia, da brincadeira. Também foi destacado que essa prática é altamente frustrante, exigindo grande limiar do psicoterapeuta para não desistir, considerando a dependência que o processo da criança mantém em relação à sua rede social, principalmente seus pais. Portanto, trabalhar com a criança é trabalhar simultaneamente com a família, tornando-se, assim, uma prática de grande complexidade.

Também foram feitas referências à demanda física que a criança requer do psicoterapeuta, sendo considerado um fator que gera cansaço nos psicoterapeutas mais velhos, que muitas vezes acabam por desistir de trabalhar com ela por não agüentarem mais

48 abaixar, levantar, sentar-se no chão ou até pular.
O sucesso do trabalho do terapeuta depende muitas vezes da habilidade/conhecimento do profissional nesse âmbito familiar. E não se sabe se os profissionais estão com formação e/ou habilitação para tais práticas e, conseqüentemente, quais são os níveis de frustração que têm vivenciado.

De maneira geral, segundo as participantes, o próprio enfoque do curso de psicologia está mais voltado ao adulto do que à criança. Num contexto mais amplo, isso repercute na formação do psicólogo e na escolha dos estudantes ao fazerem sua opção de atuação, por conseguinte, essa área cada vez mais tem um reduzido número de pessoas.

Branco (1998) traz alguns questionamentos às universidades, indagando sobre o tipo de profissional que se quer formar no curso de psicologia: se comprometido com a mudança ou com a legitimação das relações sociais.

Webber, Botomé e Rebelatto (1996, p.11) criticaram os currículos dos cursos de formação, considerando-os"mais voltados ao ensino de técnicas e modelos de atuação existentes (e consagrados) do que ao desenvolvimento de atuações profissionais socialmente significativas".

Silva (2001) afirma que atualmente se vive em busca de uma psicologia clínica que, levando em conta os saberes dos quais se dispõe, efetue intervenções nas vidas, nas relações, nas subjetividades das pessoas, sem cair em contradição ou ser rechaçada pelas próprias críticas de quem a pratica. Uma clínica que invente práxis éticas e politicamente comprometidas.

Segundo Bock (1997), a meta do psicólogo deve ser estar sempre em movimento. Um psicólogo aliado da transformação, do movimento da sociedade e dos interesses da maioria da população. Um psicólogo inquieto, conspirador, que saiba estranhar aquilo que na realidade se tornou tão familiar que chega a ser pensado como natural. Um psicólogo permeável às inovações, que aceite o desafio de, coletivamente, produzir alternativas à psicologia tradicional.

\section{Outras observações}

O trabalho com a criança foi considerado muito importante, visto que lidar precocemente com as 
questões que trazem inquietações e sofrimento é muito mais proveitoso do que lidar com elas quando já estão muito cristalizadas.

As participantes avaliaram que ser psicoterapeuta é muito gratificante, mas também muito difícil, porque o profissional é o próprio instrumento de trabalho e isto significa que, para se oferecer um trabalho de boa qualidade, é preciso estar bem pessoalmente e capacitado com conhecimentos teórico-técnicos, mediante supervisões, especializações, e isso tudo é muito dispendioso financeiramente. Entretanto, o desafio não pára por aí.

Colombo (2000) considera estimulante e desafiador o fato de que o psicoterapeuta escolhe uma atividade profissional na qual é chamado a utilizar como instrumento básico de trabalho o próprio self. Para a autora, é inquietante saber que a mágica que o terapeuta deve oferecer é a sua integridade, aqui e agora; habitar a sua morada, estar em conexão consigo, com a própria história, crenças e preconceitos, com o humano e o sagrado dentro de si. Enfim, trazer o que somente é possível, na singularidade e integridade. Whitaker e Bumberry (1990) destacaram que apenas quando se luta consigo próprio é que se fica livre para trazer a si mesmo para o consultório psicoterápico e não apenas o uniforme de terapeuta.

\section{Considerações Finais}

Quando esta pesquisa foi iniciada, uma das inquietações que a pautavam referia-se à necessidade de se buscar recursos não apenas em uma abordagem e também não somente na psicologia. Havia inicialmente uma grande convicção da necessidade e importância de buscar, em outras áreas, o apoio substancial para um pleno desenvolvimento do processo terapêutico da criança. Entretanto, tal convicção não se estendia à busca de apoio em outras abordagens, visto a incompletude de cada teoria diante da amplitude e complexidade do ser humano especialmente no que se refere a uma abordagem psicoterápica infantil. Incomodava a possibilidade de que colegas e comunidade científica considerassem tal procedimento como "eclético", "salada", embora a experiência demonstrasse que uma integração cuidadosa muito poderia enriquecer a prática clínica.
Após todo o percurso de campo e teórico, a necessidade de busca de apoio em outras abordagens também foi encontrada em algumas psicoterapeutas colaboradoras, além de ter ficado evidente na revisão literária que alguns autores compartilham essas idéias. A partir de então, tal posicionamento tornou-se mais confortável, pois se constatou que, na verdade, a inquietação suscita mudanças e não é prudente fechar-se em uma só verdade quando há o comprometimento com o avanço da ciência psicológica. Hoje, a idéia de fixar-se a um só modelo já está sendo superada e vista como possibilidade de ficar amarrado ao dogmatismo de uma ou outra corrente do pensamento constituído. Ficar preso a um só modelo é demais limitante; se, por um lado, isso possa trazer uma certa segurança; por outro, fica-se amarrado. Essas amarras contradizem o processo de autonomia que todo terapeuta propõe possibilitar que o cliente encontre. Se houver maior flexibilidade é possível adaptar os recursos às necessidades dos clientes, e não os adaptar à teoria em que se acredita.

No dizer de Fernando Pessoa, "navegar é preciso, viver não é preciso" (precisão). Portanto, diante desse viver tão impreciso, como é possível trabalhar com a subjetividade dos clientes de forma tão precisa? É preciso suportar as incertezas, deixar soltas as amarras das teorias que aprisionam para que se possa atuar, realmente, numa postura ética e estética com os clientes. Acredita-se que acima da modalidade psicoterápica está a ética, a postura do profissional diante do fazer terapêutico.

Branco (1998) afirma que o perfil do psicólogo hoje deve ser o de um profissional crítico, não necessariamente de um especialista, mas sim de um estudioso permanente das situações nas quais sua prática esteja implicada. Um profissional que se habitue a exercitar-se numa visão complexa e que perceba as contradições inerentes à sua prática e a necessidade de refazê-la, ajudando os grupos, indivíduos e instituições a eliminarem os processos de desumanização e alienação responsáveis pelo sofrimento psíquico.

A formação do psicólogo precisa possibilitar o engajamento do futuro profissional na sociedade, além 
de reelaborar o conhecimento constituído. Não se deve, com isso, eliminar as diferenças teóricas e metodológicas, apesar das finalidades comuns. O trabalho acadêmico coletivo deve explicitar e aprofundar as divergências. Além disso, a exigência por uma articulação entre teoria e prática não poderá significar ativismo que diminua o estudo das teorias. É preciso, pois, abarcar de forma profunda todas as matrizes do pensamento psicológico, em uma dinâmica de trabalho que permita o confronto de pontos de vista e projetos que reúnam vários campos do saber.

Para isso, é preciso estar atento às políticas acadêmicas que priorizam determinadas abordagens, normalmente uma ou outra dentre as mais consagradas, fechando o aluno em algumas "verdades" em termos teóricos e práticos, através dos estágios e da pesquisa, impossibilitando-o de ter acesso a uma visão mais global e com práticas comprometidas com o avanço da ciência psicológica. Para que, ratificando o pensamento de Bock (1997), seja possível formar profissionais críticos, inquietos, permeáveis às inovações e que aceitem o desafio de, coletivamente, produzir alternativas à psicologia tradicional, tudo isto aliado à transformação, ao movimento da sociedade e aos interesses da maioria da população, há de se olhar criticamente a própria atuação como clínicos e docentes, avaliando se a postura está sendo coerente com o avanço da ciência psicológica ou de especialista de conhecimento, fechado numa só verdade.

Entende-se que através do percurso percorrido na elaboração desse estudo seja possível, com base em abordagens tradicionais, promover reflexões que possibilitem avaliá-las de forma respeitosa, pelas valiosas contribuições que oferecem à prática clínica, porém, sem esquecer que são algumas possibilidades dentro de um leque de opções. Não se pode, portanto, fechar-se nessas verdades e também não se pode deixar de considerá-las como úteis e eficazes, mesmo diante do avanço da ciência.

Embora este estudo tenha partido das práticas tradicionais, não se restringiu a apenas uma abordagem e também possibilitou algumas reflexões para além delas, através dos temas emergentes nas entrevistas. No entanto, fica a contribuição para futuras pesquisas e também a reflexão de que as práticas tradicionais são muito importantes, mesmo com todo avanço da psicologia. Mas, como clínicos e docentes formadores de psicólogos, é necessária uma certa permeabilidade que possibilite crítica e flexibilidade para acompanhar a evolução e exercer uma prática para além do instituído, a serviço da humanização e desalienação.

Vale ressaltar, também, a localidade onde essa pesquisa foi realizada - realidade Pernambucana, ficando também a sugestão para futuras pesquisas em outras regiões brasileiras.

\section{Referências}

Axline, V.M. (1980a). Dibs: em busca de si mesmo. Rio de Janeiro: Agir.

Axline, V.M. (1980b). Ludoterapia: a dinâmica interior da criança. Belo Horizonte: Interlivros.

Bermúdez, J.G.R. (1997). Teoría y técnica psicodramatica. Buenos Aires: Paidós.

Bock, A.M.B. (1997). Formação do psicólogo: um debate a partir do significado do fenômeno psicológico. Revista Psicologia Ciência e Profissão, 17 (2), 37-42.

Branco, M.T.C. (1998). Que profissional queremos formar? Revista Psicologia Ciência e Profissão, 18 (3) 28-35.

Colombo, S.F. (2000). Em busca do sagrado. In H.M. Cruz. Papai, mamãe, você... E eu? Conversações terapêuticas em famílias com crianças (pp.168-88). São Paulo: Casa do Psicólogo.

Dorfman, E. (1974). Ludoterapia. In C. Rogers. Terapia centrada no paciente (pp.269-317). São Paulo: Martins Fontes.

Epston, D. (1997). "I am a bear": discovering discoveries. In C. Smith \& D. Nylund. Narrative therapies with children and adolescents. New York: Guilford Press.

Ferrari, D.C.A. (1984). A postura do psicodramatista no Psicodrama de criança. Revista da Febrap, (2), 55-60.

Grandesso, M.A. (2000a). Sobre a reconstrução do significado: uma análise epistemológica e hermenêutica da prática clínica. São Paulo: Casa do Psicólogo.

Grandesso, M.A. (2000b). Quem é a dona da história? In H.M. Cruz. Papai, mamãe, você... Eeu? Conversações terapêuticas em famílias com crianças (pp.101-22). São Paulo: Casa do Psicólogo.

Molina-Loza, C.A. (2002, maio). Os canários da minha avó, "as asas da imaginação" ou "conta para o cliente, que ele próprio se reconta" [on-line]. Disponível em: http:// www.abratef.org.br/meioartigos.htm

Oaklander, V. (1980). Descobrindo crianças: abordagem gestáltica com crianças e adolescentes. São Paulo: Summus. 
Oaklander, V. (1994). Gestalt Play Therapy. In K.J. O'Connor. Handbook of play therapy. V.2: advances and innovations. Willy Series on personality processes (pp.143-56). New York: The Guilford Press.

Oaklander, V. (1999). Group play therapy from a Gestalt therapy perspective. In D.S. Sweeney, (Ed). The Handbook of group play therapy (pp.162-75). New York: The Guilford Press.

Oaklander, V. (2000). Short-Term Gestalt play therapy for grieving children. In H.G. Kaduson \& C. E. Schaefer, (Ed). Short-Term play therapy for children (pp.28-52). New York: The Guilford Press.

Osório, L.C., \& Valle, M.E. (2002). Terapia de famílias: novas tendências. Porto Alegre: Artmed.
Silva, E.R. Psicologia Clínica, um novo espetáculo: dimensões éticas e políticas. Revista Psicologia Ciência e Profissão, 21 (4),78-87.

Weber, L.N.D., Botomé, S.P., \& Rebelatto, J.R. (1996). Psicologia: definições, perspectivas e desenvolvimento. Psicologia Argumento, 29, 9-28.

Whitaker, C.A., \& Bumberry, W.M. (1990). Dançando com a família:uma abordagem simbólico-experiencial. Porto Alegre: Artes Médicas.

Recebido para publicação em 23 de março e aceito em 21 de junho de 2004 
